\title{
ORIGEN Y DESARROLLO DEL GRAFISMO RUPESTRE NATURALISTA POSTPALEOLÍTICO EN EL MEDITERRÁNEO
}

\author{
Origine et développement du graphisme rupestre naturaliste \\ postpaleolithique dans la méditerranée peninsulaire
}

\author{
Carme Olària*
}

Recibido el 2 de octubre de 2007. Aceptado el 5 de noviembre de 2007.

\begin{abstract}
Resumen. En este trabajo planteamos la problemática del origen y evolución del grafismo naturalista postpaleolítico en el Mediterráneo peninsular, teniendo en cuenta los contextos arqueológicos que lo acompañan y las temáticas que se desarrollan en el mismo. Otorgando para su interpretación socioeconómica la prioridad a los contenidos temáticos de dichos grafismo sobre los estilos detectados.

Palabras clave: Arte rupestre. Postpaleolítico. Origen. Cronología. Evolución. Temáticas.
\end{abstract}

Résumé: Dans ce rapport nous projetons la problématique de l'origine et l'évolution du graphisme naturaliste post paléolithique dans la Méditerranée péninsulaire, en tenant compte des contextes archéologiques qui l'accompagnent et ce qui est thématiques qui sont développées dans ce dernier. En accordant la priorité pour son interprétation socio-économique aux contenus thématiques de propos graphisme sur les styles détectés. Mots clef: Art rupestre. Postpaléolithique. Origine. Chronologie. Évolution. Thématiques.

\section{INTRODUCCIÓN}

Este artículo lo dedicamos a la memoria del profesor Dr. Eduardo Ripoll Perelló, uniendo nuestra estima y admiración por sus trabajos, y la dirección de las excavaciones y del Museo de Ampurias, a cuyos cursos asistimos desde que iniciamos la carrera, y la Dirección del Museo Arqueológico de Catalunya. Con el tiempo nos unió una buena amistad que nunca olvidaremos

Hoy en estas líneas hemos deseado plantear algunos temas de debate que todavía siguen candentes y sin resolver concernientes a las representaciones gráficas postpaleolíticas.

\section{SOBRE EL ORIGEN DEL GRAFISMO POSTPALEOLÍTICO}

Los últimos descubrimientos de grabados de tipo mobiliar 0 al aire libre han aportado nuevas perspectivas de estudio para evaluar el origen del llamado "arte levantino".
Todo parece apuntar que se iniciaría a partir de una técnica diferente a la propia aplicación de pigmentos, y la técnica inicial sería el grabado somero o grafitado, similar al que hallamos en los contextos magdalenienses finales, epimagdalenienses, epipaleolíticos y mesolíticos, expresados mayoritariamente en los conjuntos del arte mobiliar, pero también en el llamado arte parietal especialmente abundantes en la franja mediterránea peninsular.

Evaluamos la cantidad de hallazgos de plaquetas y guijarros grabados en el ámbito mediterráneo, en un período que perdura desde el Paleolítico superior final, Epipaleolítico y Mesolítico, que a su vez en algunos casos no sólo usa el grabado sino también utiliza los pigmentos en dichas ornamentaciones. Nos interesa investigar estas expresiones gráficas grabadas, originadas en la etapa del Paleolítico superior, y cómo se hicieron tan prolíferas durante la fase Magdaleniense final en la vertiente mediterránea, de alguna manera continuaron en los subsiguientes periodos culturales, unos

$\left.{ }^{*}\right)$ Cátedra de Prehistoria. Laboratori d'Arqueologia Prehistòrica. Universitat Jaume I de Castelló. olaria@ @is.uji.es 
sobre plaquetas o guijarros, y otros sobre paneles al aire libre, prosiguiendo una honda tradición, que quizá pudo abocar a la inicial realización primero de un tipo de arte rupestre al aire libre grabado, después al uso de una técnica mixta grabada y pintada, para más tarde abocar al uso exclusivo de aplicación de pigmentos. Esta dinámica de antecedentes técnicos bien pudiera haber constituido el origen del Ilamado arte levantino.

Será necesario para ello considerar no sólo los tipos de yacimientos dónde se han encontrado estos vestigios de arte mobiliar, sino también los territorios que ocuparon y sus relaciones con los contextos arqueológicos, si los hubo. De la misma manera tendremos que considerar las figuraciones grabadas al aire libre, en territorios levantinos, al igual que las técnicas mixtas compuestas de grabado-pintado, que se encuentran en estos mismos territorios, y por último los yacimientos próximos a conjuntos de arte al aire libre.

Por otra parte deseamos facilitar la lectura de este trabajo, definiendo los conceptos que usamos. Asi el Epimagdaleniense, será un momento "bisagra" entre el Magdaleniense y el Epipaleolítico inicial; a menudo difícil de separar (Epimagdaleniense / Epipaleolítico inicial) pues lo tipos líticos básicamente identificados por la presencia de los abruptos y laminitas son comunes a ambos. Por otra parte el Epipaleolítico a lo largo de su evolución seguirá conservando estas mismas tradiciones líticas en su cultura material, pero también unas mismas premisas económicas de subsistencia cazadora-recolectora-pescadora. Mientras que en el Mesolítico se operan cambios substanciales en las industrias líticas, con la presencia cada vez más numerosa de los geométricos; además a su economía de subsistencia se incorporan cambios paulatinos conducentes a la economía de producción en algunos casos, como modos de horticultura, introducción de domesticación de algunos animales y ampliación de sus técnicas de almacenaje.

Los grabados al aire libre, son probablemente las primeras manifestaciones que preceden al Ilamado "arte levantino". Más tarde estos grabados se combinarán con las técnicas de pintura, usados para señalar los contornos y /o los detalles anatómicos del animal. Esta combinación de aplicación de pigmentos junto al grabado se recoge en abundancia en los yacimientos mesolíticos y epipaleolíticos peninsulares del Mediterráneo.

El caso del abric dels Moros de Cogul (Lleida) sería una buena e interesante muestra de esta evolución. Por una parte se aprecian tres animales totalmente grabados, que ya fueron descritos por Almagro Basch (1952: 26), uno de ellos representando un cáprido que sin duda encuentra unas analogías con los grabados de barranco Hondo (Castellote, Teruel) y también con los encontrados en abric d'en Meliá (Serra d'en Galcerán, Castellón). Los restantes cuadrúpedos de abric dels Moros, un bóvido y un animal indeterminado, se pueden incluir en esta fase de expresiones gráficas efectua- das mediante la técnica del buril. Si bien en casos los trazos grabados oscilan en un surco más o menos profundo, la mentalidad que los produjo, encuentra sus antecedentes en los grabados mobiliares del Magdaleniense final y el Epimagdaleniense. Más adelante esta técnica del grabado parece reducirse al empleo único del perfilado, en casos también para resaltar algunas características anatómicas del animal; posteriormente el perfilado grabado probablemente se sustituyó definitivamente por el uso del contorno del trazo pintado caligráfico fino derivado del uso "de pluma", que otorgaba más relieve y realismo a la figura.

Otra cuestión que nos parece interesante resaltar, puesto que se evidencia con claridad, también en abric dels Moros, es la referente a las temáticas que se plasman en los soportes rocosos. En efecto, es común que los animales de gran biomasa, solitarios o con tendencia al estatismo, encuentren en este mismo conjunto de Cogul otras consecuencias resultantes de la aplicación del grabado en el contorneado de los cuerpos de grandes bóvidos o cérvidos, como también pudo darse en el abrigo dels Gascons (Cretas) y en Roca dels Moros (Calapatá). Recordemos que estas representaciones llamadas "naturalistas" por varios especialistas, se consideraron los precedentes de las posteriores escenificaciones dinámicas del más puro "arte levantino", especialmente aquellas cuyo pigmento oscila entre los colores del negro al blanco marfil o anaranjado.

Pero también es interesante observar la escenificación compuesta por el binomio animal-arquero realizada absolutamente con la técnica del grabado (grafitado) somero, como se contempla en Barranco Hondo (Castellote, Teruel). Lo cual indica que los ensayos de expresiones gráficas anteriores al más puro estilo levantino pintado, fueron previamente realizadas por otra técnica, también bien conocida, como la del mismo grabado. Los indicadores del estilo de las figuras animales y humanas de barranco Hondo, parece plausible que posteriormente fuesen imitados en las plasmaciones pictóricas más evolucionadas correspondientes al arte llamado levantino. Sin embargo la técnica del grabado con ausencia de pigmento, como ocurre en Barranco Hondo y abric d'en Meliá (Serra d'en Galcerán, Castellón) por ejemplo, sin duda pertenecen a unas tecnologías más arcaizantes si son comparados con las técnicas y estilos pictóricos del más típico "arte levantino".

Lo que resulta obvio, a nuestro juicio, es que el típico "arte levantino"pintado no se originó "espontáneamente", si tenemos en cuenta los precedentes grabados o las técnicas mixtas compuestas de pigmentos y grabados. Tampoco creemos que se originarán debido a un préstamo cultural del neolítico antiguo, pues a todas luces las técnicas (el grabado y trazo de pluma), así como las temáticas cinegéticas, míticas e iniciáticas corresponden a un mundo de creencias propio, perteneciente a comunidades de economía de subsistencia y a creencias que giran entorno al mundo silvestre o Natural. 
La cuestión planteada es si existió una evolución tanto en las técnicas como en las temáticas, así como en la composición, hasta alcanzar las conocidas escenificaciones, llenas de dinamismo y narrativa, típicas del arte pictórico levantino.

Si consideramos que el arte localizado en el área mediterránea peninsular es un "mundo artístico" que representa un lenguaje gráfico diferente al clásico modelo del llamado "arte franco-cantábrico", deberíamos preguntarnos qué dinámica interna produjo estas variables diferenciadoras en el arco mediterráneo de nuestra península; así mismo nos deberíamos cuestionar acerca de las causas de estas diferencias constatadas en este territorio mediterráneo ibérico ¿la tradición gráfica del paleolítico superior se adapto e innovó a través de otros soportes y técnicas, como aparece en Cova del Parpalló?

Las últimas etapas del Paleolítico superior producirán unas expresiones gráficas mayoritariamente mobiliares, cuando menos en el área mediterránea, como ya hemos indicado, y la gran mayoría de estas expresiones gráficas son efectuadas con la técnica del grabado somero; pero no olvidemos que anteriormente esta misma técnica fue combinada con la pintura en el mismo arte mobiliar, caso de la cueva del Parpalló (Gandia, Valencia). Pero a pesar de estos antecedentes no podemos poner en duda que para el área mediterránea peninsular es especialmente la técnica del grabado la que se impone en todo el arte mobiliar del Magdaleniense final y Epimagdaleniense, y apenas se introdujo el clásico "arte rupestre". Es posible que la falta de grandes formaciones cársticas, que sí encontramos en el Sur, actual Andalucía, produjera otras respuestas en las expresiones gráficas mediterráneas.

En este punto debemos hacer una reflexión acerca del mismo Epimagdaleniense, que siempre ha sido una fase cultural difícil de determinar, e incluso a menudo se confunde con el Epipaleolítico inicial, como ya hemos dicho anteriormente, puesto que los tipos líticos microlaminares con retoque abrupto, que acompañan a ambos, conservan fuertes similitudes, lo mismo ocurre con su arte mobiliar grabado. Por tanto nadie propondría que existió una ruptura cultural, analizando su cultura material, entre el Epimagdaleniense y Epipaleolítico de microlaminitas, y si no existió en las herramientas de trabajo, parece difícil admitir que existiera en su lenguaje gráfico y simbólico.

En cuanto al Ilamado Epipaleolítico de geométricos, que personalmente preferimos denominar Mesolítico, también generó en una serie de elementos gráficos, tanto en el arte mobiliar como en el parietal, buen ejemplo serían los restos de arte mobiliar grabados y pintados de cueva de Cocina (Dos Aguas, Valencia), o también los grabados del abric de Sant Gregori (Falset, Tarragona), los cuales no se plasmaron exclusivamente sobre objetos mobiliares sino que por las evidencias podemos afirmar que también se realizaron sobre paneles rocosos.
Otra cuestión que no debemos olvidar es que el "arte cavernario" paleolítico se trasladará en sus etapas finales al exterior de la caverna e incluso sobre grandes bloques rocosos erráticos no vinculados directamente con mundo subterráneo de la caverna, como ya fue observado por Laming Emperaire y Leroi Gourhan; este fenómeno se dará en el magdaleniense final.

Por estas razones nos parece más plausible formular una teoría basada en la evolución de lenguajes gráficos heredados de la memoria histórica de los diferentes grupos humanos que desarrollaron diferentes culturas desde el magdaleniense final, epimagdaleniense, epipaleolítico y mesolítico hasta alcanzar procesos de neolitización, que de forma muy elocuente se muestran en las propias imágenes de este grafismo.

Así pues defendemos que existió un "filum" común que se fue modificando hasta alcanzar cuando menos el $V$ milenio. Pero este filum se olvidará totalmente en cuanto se introduzcan los primeros ensayos agrícolas cerealistas, y otro tipo de grafismo impregnará el mundo de las creencias, puesto que el cultivo de la Tierra marcará un paso trascendental en la incorporación de las primeras deidades femeninas vinculadas al mundo doméstico agrícola, que provocará la aparición del mundo religioso. Así pues algunos grupos humanos reflejan en sus lenguajes gráficos un nuevo imaginario alrededor de una deidad femenina - deidad de la Tierra-, que lo podemos apreciar con claridad a través de las iniciales imágenes del llamado "arte macroesquemático" y esquemático.

A la vista de cómo se van sucediendo los descubrimientos en el ámbito mediterráneo peninsular, creemos que no podemos sino aceptar la existencia de una evolución evidente, iniciada en el arte mobiliar grabado/pintado del magdaleniense final epimagdaleniense y los conjuntos al aire libre grabados/pintados que usaron las mismas técnicas gráficas en los periodos epipaleolíticos-mesolíticos y los desarrollados en los primeros procesos de neolitización en territorios levantinos.

Más tarde estas técnicas de grabado fino se combinarán también con pigmentos, especialmente para representar grandes cuadrúpedos, como bóvidos y cérvidos, hasta que finalmente este trazo grabado contorneando la figura o señalando ciertos rasgos anatómicos será completamente "olvidado" en favor de la imposición definitiva del ya conocido trazo fino caligráfico o "de pluma", que ahora caracterizará al más puro estilo levantino.

Por otra parte es necesario señalar que las técnicas nunca fueron excluyentes, así encontramos como definitoria la técnica de "pluma" para el Ilamado "arte levantino", pero sin embargo también convive con ella la técnica del pincel en un periodo de transición hacia modalidades gráficas de transición al esquemático pero con grafía naturalista (Sierra de Cuenca: Tio Modesto, Selva Pascuala, etc)

Las temáticas sí que experimentaran un cambio sustancial en función de las sociedades y sus economías: en este 
sentido podríamos decir que la tradición de las economías de subsistencia fundamentarán las temáticas básicamente en la caza; pero en su transición hacia la neolitización incorporarán escenas de domesticación (caballo en Selva Pascuala (Villar del Humo, Cuenca); recolección en Cinto de las Letras (Dos Aguas, Valencia), pastoreo en Cañada de Marco (Alcaine, Teruel), etc.

Al igual que los detalles anatómicos en algún caso, como ocurre con las manos abiertas del periodo de transición hacia la grafía esquemática, mientras que en la grafía levantina nunca existirá este detallismo anatómico para las figuras humanas.

De igual modo los grandes animales centrales dentro del panel, bóvidos y cérvidos en su mayoría, estarían dentro de las características más antiguas de tipo naturalista.

\section{DISPERSIÓN GEOGRÁFICA DE LOS YACIMIENTOS}

Definiremos tres grupos correspondientes respectivamente a los conjuntos totalmente grabados que presentan únicamente zoomorfos, a aquellos que usan el grabado únicamente incluyendo la figura humana y conforman una escenificación y finalmente al perfilado grabado de una figura posteriormente pintada.

\section{Grabados de zoomorfos}

Cova Fosca (Ares del Maestre, Castellón). Una de las plaquetas grabadas halladas en esta cavidad. La plaqueta que presentamos pertenece a una cota [-265/-275 cm]. Este rebaje se encuentra datado por $\mathrm{C}-14$ entre un $8.880 \pm 200 \mathrm{BP}$ y $9.460 \pm 160 \mathrm{BP}(6.930 \pm 200 \mathrm{BC}$ y $7.510 \pm 160 \mathrm{BC})$ sin calibrar, relativas a los rebajes [-270] y [278] respectivamente. En es- ta plaqueta se aprecian con claridad dos cabezas de cérvidos mirando a la derecha, a pesar de que la técnica de grabado es del tipo grafitado o somero. Las cabezas presentan un mismo diseño pseudotriangular que hemos apreciado en Abric d'en Meliá y Barranco Hondo. La superficie de la plaqueta se encuentra atravesada con trazados lineales largos y cortos, asi como con algún zig-zag. En el contexto mesolítico y epipaleolítico de Cova Fosca hemos hallado otras plaquetas grabadas, en muchos casos acompañadas con restos de pigmentos de ocre. En este caso concreto que aportamos como novedad no cabe duda que perteneciera a un momento mesolítico.

Abric d'en Meliá (Serra d'en Galcerán, Castellón). Este conjunto ubicado a poca distancia de los territorios levantinos de Valltorta y Parque de Gasulla ha sido atribuido a un periodo magdaleniense, por encontrar paralelos en el diseño de animales con algunas plaquetas de Parpalló. (Martínez Valle, Guillem y Villaverde, 2003).

Sin embargo, según nuestro criterio, los nuevos descubrimientos de Barranco Hondo (Castellote, Teruel) presentan fuertes analogías con los diseños de animales de Abric d'en Meliá, especialmente en los largos cuellos, las patas de líneas acabadas por dos trazos convergentes, los trazos de incisiones grabadas en el interior de los cuerpos y la estructura de las cabezas pseudotriangulares, si bien en Barranco Hondo presentan un morro achatado. Naturalmente llama la atención como unos y otros grabados pueden estar tan alejados en el tiempo, uno, como Abric d'en Meliá publicado (Martínez Valle, Guillem y Villaverde, 2003) como perteneciente al Paleolítico superior magdaleniense y otros como Barranco Hondo publicado como perteneciente al $\mathrm{V}$ milenio, es decir, culturalmente del Neolítico antiguo final al Neolítico medio inicial (Guillem Calatayud y Martínez-Valle, en Utrilla y Villaverde, 2006: 105-122).

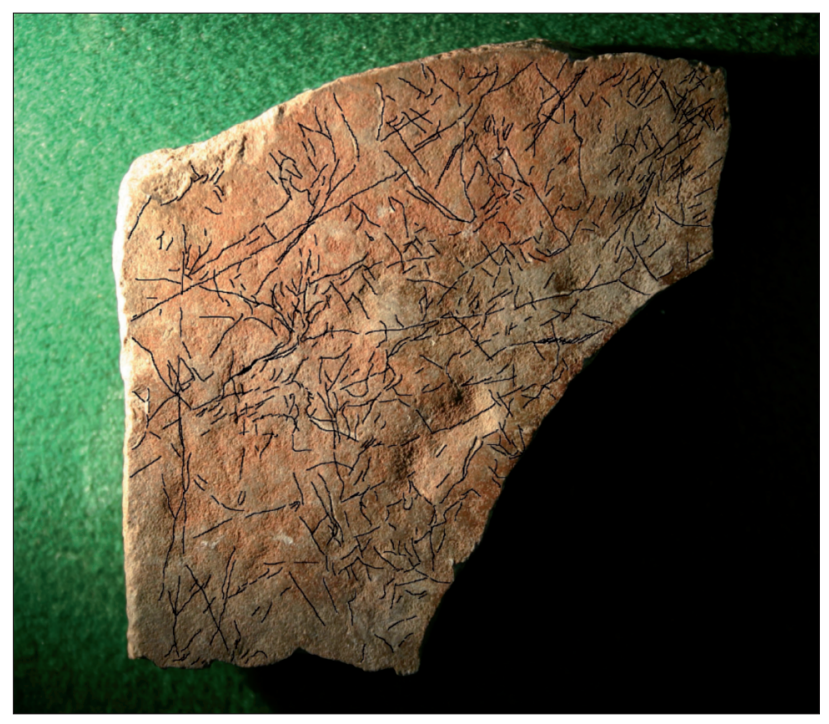

- Figura 1. Plaqueta grabada de Cova Fosca (Ares de Mestre, Castellón).

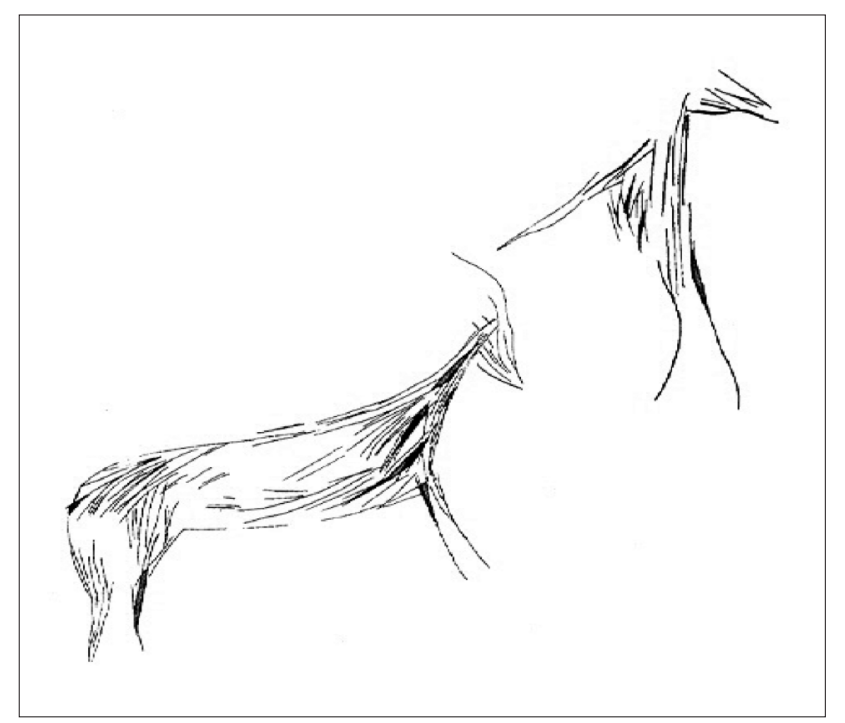

A Figura 2. Cuadrúpedos grabados de Abric d'en Melià (Serra d'en Galcerán, Castellón). 
Esta clara contradicción creemos que se debería matizar pues la sola presencia humana no indicaría un salto cronológico de casi 10.000 años en una y otra estación rupestre. Es cierto que Abric d'en Meliá no contiene figuras humanas, o cuando menos no han sido halladas, pero no creemos de ningún modo que la incorporación de la figura humana fuera tan tardía en las representaciones grabadas, recordemos a este respecto que el retrato de figuras humanas se encuentra con profusión en los cantos grabados del Magdaleniense final o VI. A nuestro juicio y así lo hemos publicado (Olaria, C.; Aguilella, G.; Gómez, J. L.; Gusi, F. ,2005) la estación rupestre de Abric d'en Melià pensamos que sería coherente atribuirlo a un momento inicial de epipaleolítico, mientras que Barranco Hondo quizá tenga una evolución en el tiempo posterior pero no más allá de fines de este periodo o como mucho de inicios del mesolítico.

Barranco de Arriuelo o Fuente del Cabrerizo, (Teruel). Se trata de una pared vertical localizada en el angosto barranco de Arriuelo, donde se encontró un grabado de équido de surco ancho y profundo, cuyo perfil viene complementado por una serie de trazos cortos que marcan sus crines y el pelaje interior del animal; las patas y cola se efectuaron con simples trazos lineales. También se descubrió un cérvido grabado de trazado más superficial. Las sospechas de falsedad de estos grabados son totalmente injustificadas, según ya indicó Beltrán (1968: 136).

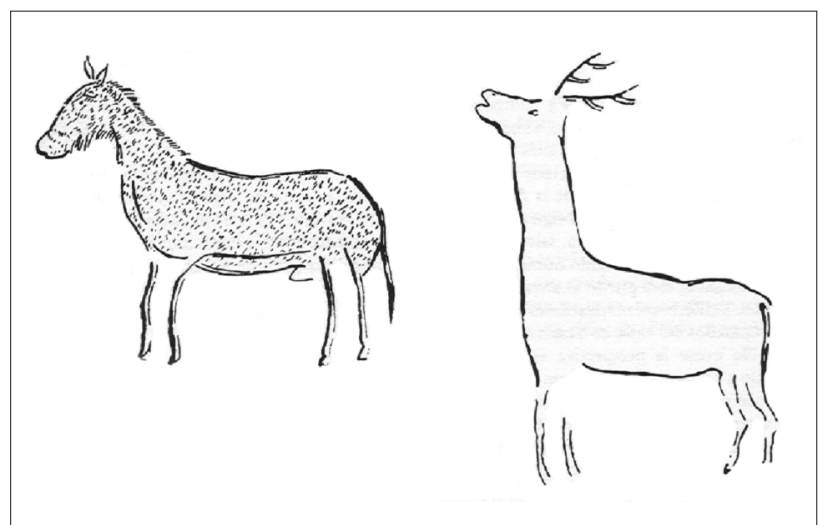

A Figura 3. Grabados del Barranco del Cabrerizo (Teruel).

Abrigo del Tossal de la Roca (Vall d'Alcalá, Alicante). En 1983 Aparicio publicó por primera vez una gruesa piedra de superficie plana procedente de las remociones clandestinas en el interior de la cavidad. Dicha piedra fue grabada representando a un macho cabrio de largos cuernos, el cual se encuentra superpuesto sobre la cabeza y cuello de una cierva, ambas figuras van acompañadas de múltiples trazos lineales grabados, y una gran mancha de ocre rojo.

Posteriormente en las excavaciones de Cacho (1995; 2001) se identificaron seis piezas:
- Canto calizo de tipo retocador en cuyo anverso aparece grabado con un zorro o un cánido.

- Plaqueta caliza que muestra en el anverso una probable quijada de animal indeterminada, y en reverso un conjunto de grabados lineales.

- Canto calizo donde aparece grabado un animal indeterminado, toro o ciervo; y el reverso aparece tiznado de ocre.

- Fragmento de plaqueta de greda cuyo anverso está lleno de ocre con un grabado de la cabeza y cuello de una cierva, además de trazos lineales desordenados.

- Fragmento canto calizo en cuyo anverso se aprecia una cierva grabada, que no presenta la línea del lomo ni los cuartos traseros. Algunos autores ven en esta cierva paralelos con los grabados de Cova Fosca de la Vall d'Ebo.

- Finalmente cabe citar un fragmento pequeño de hueso, de tipo espátula, con grabados geométricos en ambas superficies.

Abrigo dels Moros de Cogul (Lérida). Se observa un toro silueteado con grabado (Breuil, 1909: 4-12), si bien Cabré defendió la existencia de más grabados y la existencia de un pequeño cáprido (Cabré, 1915). Por su parte Almagro Basch (Almagro, 1952: 26), también reconoció a un toro con grabado. Los demás investigadores, que posteriormente lo han estudiado, no aceptan la existencia de dichos trazos grabados.

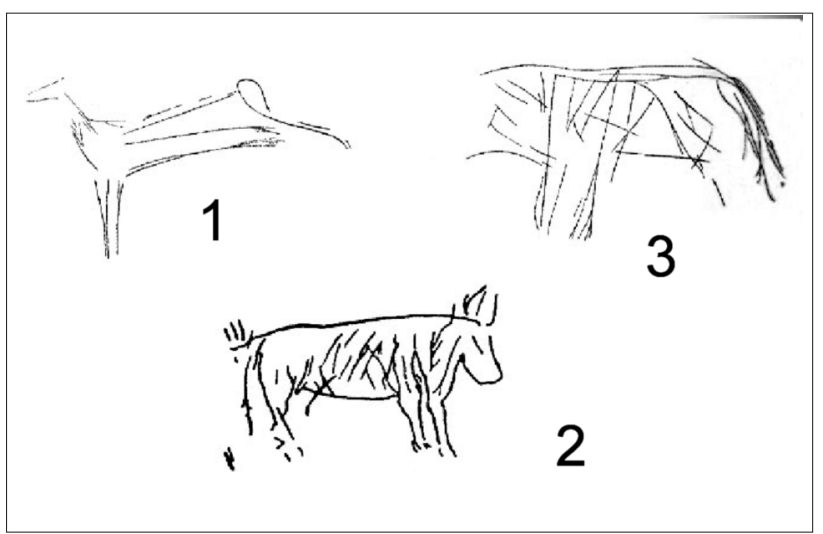

A Figura 4. Animaales grabado de Abric dels Moros (Cogul, Lleida).

Abrigo de Sant Gregori (Falset, Tarragona). Recogiendo las antiguas descripciones de Vilaseca (1973: 48-53), este importante yacimiento, proporcionó entre los cinco niveles identificados una plaquita grabada representando a una cierva, y que como decía finalmente Vilaseca "Desde luego nos parece que su filiación debe buscarse dentro de un periodo mesolítico "aziliense" al que hemos atribuido el nivel 5 y que podríamos suponer epigravetiense." A pesar de esta nomenclatura, sin duda debía referirse al nivel 2, donde describe el hallazgo de la plaqueta. Llama la atención que cite también 


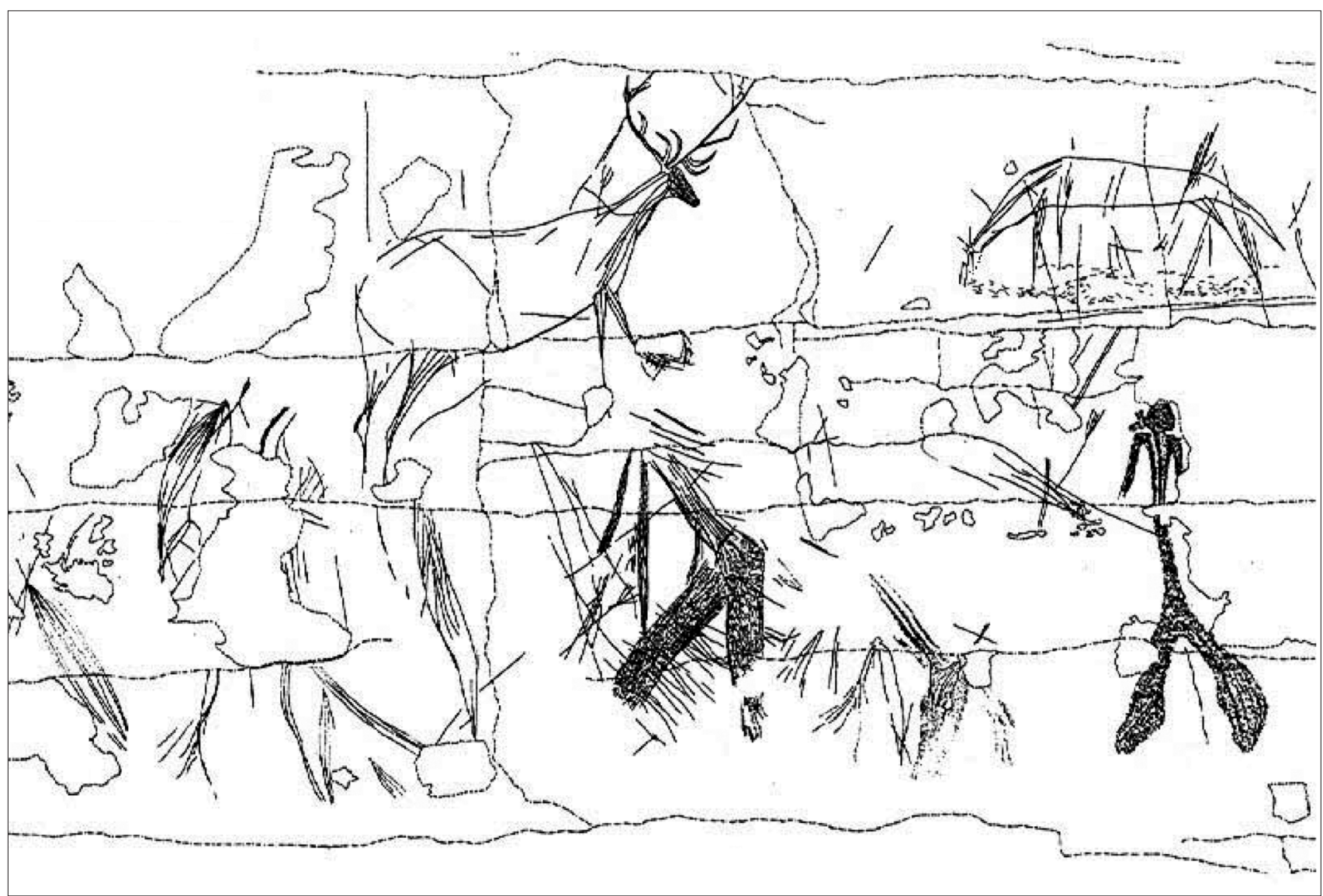

A Figura 5. Vista general de los grabados del Barranco Hondo (Castellote, Teruel).

el hallazgo "de hueso con incisiones oblicuas" lo cual nos induce a pensar si se trataría de un fragmento de base de arpón o azagaya, teniendo en cuenta el número de puntas de dorso rebajado de unos $4 \mathrm{~cm}$ de longitud, creemos que el nivel 2 donde se encontró la plaqueta grabada podría atribuirse a un momento epimagdaleniense/epipaleolítico inicial, lo cual la encuadraría perfectamente en el contexto del arte mobiliar que se desarrolló masivamente en el Mediterráneo peninsular a fines del tardiglaciar e inicios del holoceno, por lo que culturalmente creemos, cuando menos teóricamente, que se trata de un periodo epipaleolítico.

\section{Grabados de zoomorfos acompañados de antropomorfos}

Barranco Hondo (Castellote, Teruel). Las primeras noticias sobre este interesante conjunto grabado fueron dadas a conocer por Sebastián (1992). Recientemente ha sido publicado un estudio monográfico editado por Utrilla y Villaverde (2006).

El interés de estos paneles exclusivamente grabados, que no representan exclusivamente animales sino que van acompañados por figuras humanas mostrando arqueros, cuyo estilismo recuerdan al de las posteriores figuras de ar- queros de otras estaciones levantinas totalmente pintadas, como las Ilamadas del tipo "Centelles" en Valltorta. Por tanto el barranco Hondo nos presenta sin duda un precedente grabado cuya composición y estilo encuentran ciertas analogías con el arte pictórico levantino especialmente para las figuras humanas, sin embargo la manufactura técnica nos retrotrae a unos momentos anteriores quizás epimagdalenienses pero más probablemente epi-mesolíticos. Por otra parte si observamos las manufacturas grabadas que se han usado en la realización de los animales, sus anatomías tienen marcadas analogías con las utilizadas en abric d'en Meliá. Naturalmente en este estudio de Barranco Hondo se hacen los posibles por modernizar el conjunto grabado y se buscan, forzadamente a nuestro juicio, las analogías con el típico arte levantino, tanto en el tiempo (de la "neolitización", pero posterior al V milenio, es decir del Neolítico pleno-medio) como en el espacio (dado que los montaraces cazadores levantinos sufrieron un retraso en la neolitización hasta recibir el contacto de las áreas "neolitizadas" por la "colonización" según se indica en el estudio citado). Desde luego estas conclusiones mediatizadas por el llamado "modelo dual" no tienen ninguna validez objetiva ni demostrable. 


\section{Grabados asociados a pintura}

Racó de Molero (Ares del Maestre, Castellón). En este conjunto se aprecia la figura de un toro con grabado fino que se dispuso para marcar su silueta rellena de pintura en su interior, según Beltrán (1968: 184) Este grabado fue descubierto por Beltrán en 1964. El grabado presenta un surco fuertemente patinado que muestra su antigüedad; la cabeza forma un pequeño relieve pues fue aprovechado un accidente natural del soporte rocoso. En la fotografía que adjunta Beltrán (1968: 185, fig.118) se aprecia claramente la existencia de este bóvido, cuyo hocico, ojo y cuernos están notablemente resaltados. En la actualidad sorprendentemente se ha negado la existencia de la técnica del grabado que observó Beltrán.

Cocina (Dos Aguas, Valencia). La Cueva de la Cocina (Dos Aguas, Valencia) se sitúa cerca del barranco de Las Letras y el Cinto de la Ventana (Dos Aguas, Valencia). En este yacimiento se identificaron cuatro fases de evolución:

- Cocina I (fase A), perteneciente al VII milenio con industrias geométricas de trapecios y macrolascas.

- Cocina II (fase B), datada relativamente en la primera mitad del VI milenio, con industrias geométricas de triángulos y triángulos tipo Cocina con los lados cóncavos y espina central.

- Cocina III (fase C) de la segunda mitad del VI milenio con industrias de segmentos y láminas de dorso, además de cerámica impresa del tipo cardial.

- Cocina III (fase D) que representa el neolítico final y otras etapas culturales sucesivas.

En este yacimiento se halló "...un buen conjunto de grabados y pinturas sobre plaquetas y guijarros" (Pericot, 1945), compuesto por 28 pequeñas plaquetas decoradas, tres de ellas en ambas caras, con un grabado muy fino, además de una plaqueta que se descubrió posteriormente; todas pertenecian al nivel II. Pericot (1945: 53) indica que una de ellas presentaba un perfil de animal, señala que se trata posiblemente de un cáprido, pero puede ser una cierva estilizada. Más tarde en la revisión de otros autores (Aparicio, 2006: 275) detalla la aparición de "un canto de caliza con una pequeña cabeza de cierva estilizada" del estrato $\mathrm{H} 1$, fase Cocina II; y dos presentaban una combinación mixta de pintura y grabado. También este mismo autor (Aparicio, 2006, 275) indica la presencia de "cantos pintados con manchas subcirculares rojas y ocres" encontradas en el estrato $\mathrm{H} 2$ de la fase Cocina I.

Las pinturas eran monocromáticas de color rojo mayoritariamente, aunque existen algunas en tonos ocres.

Las plaquetas grabadas con trazos lineales correspondian al nivel II de Pericot y a la fase Cocina II de Fortea. La cronología relativa se estimó en la primera mitad del VI milenio.
Por otra parte se identificó "arte levantino" en la entrada de la cavidad, posteriormente estudiado (Grimal, 1995: 324).

Hay que señalar que también en este yacimiento se encontraron grabados esquemáticos en el suelo de la entrada, y otro sobre un gran bloque de desprendimiento, lo cual nos indicaría una posible pervivencia en la Edad del Bronce o quizá también en época medieval.

Los Toricos del Padro del Navazo (Albarracín) En un friso de unos tres metros de longitud se sitúan cinco grandes toros de estilo naturalista, junto con otros cinco más de pequeño tamaño y un cérvido; en el centro, y ubicados en una pequeña oquedad, se ubican cinco pequeños arqueros. Los colores de las figuras son en general en un "blanco lechoso y pajizo" de un pigmento espeso, pese que en algunas figuras se perciben unos trazos en rojo; uno de los toros está pintado en negro así como las figuras humanas; el tono rosado nos señala Beltrán (1968: 137) se debe a mera tonalidad del soporte.

Para Beltrán los animales grandes pintados en blanco serían los más antiguos; los animales más pequeños serían posteriores según el criterio de Beltrán, dado que uno de éstos se superpone sobre otro mayor. Apuntaba Beltrán que probablemente en este abrigo existiera un segundo momento de ejecución para incorporar las figuras de arqueros.

En uno de los bóvidos de color blanco-pajizo, se aprecia su contorno o perfil grabado junto con trazos de grabados lineales. (Beltrán, 1968; Sebastián, 1986-1987).

La Cocinilla del Obispo o Callejón del Plou (Prado del Navazo, Albarracín, Teruel). También en este abrigo se encuentra la pintura acompañada de perfilado con técnica de grabado. En el friso se pueden contemplar ocho toros, número similar al de Los Toricos del Prado, y a pesar de las contradicciones, ya que Cabré (1915: 186) apreció el grabado en todos los bóvidos, lo más plausible es que cuatro de ellos lo estén con seguridad. El panel de figuras se ha tratado con técnica de pintura, más grabado para el perfilado de las mismas. Se presentan en el soporte además del total de ocho bóvidos acompañados con tres ciervas pequeñas; cinco de los toros son más grandes que los restantes y entre ellos uno solo, de color pálido anaranjado, se encuentra perfilado en grabado fino, si bien Beltrán (1968: 141) señaló que la totalidad de las figuras presentaban un somero grabado que marcaba su contorno.

Se ha estudiado posteriormente por Piñón (1982: 60-61) y Collado (1992).

También es interesante recordar que Almagro Basch en 1943 encontró industrias líticas de tipología epipaleolítica en las proximidades de este abrigo, y en las cercanías del abrigo de Los Toricos del Prado de Navazo (Beltrán, 1968: 137). 
Ceja de Piezarrodilla (Albarracín, Teruel). Se trata de la figura de un toro que fue repintado en tres ocasiones, la última en un tono pálido anaranjado que cubrió el pigmento negro anterior. El grabado se presenta en todo el contorno de la figura del animal. Su estudio lo realizó Piñón (1982: 151).

Abrigo del barranco de las Olivanas o El Prado de las Olivanas (Tormón, Teruel). Un panel de cuarenta figuras en las que hay toros, antropomorfos y ciervos. Parece que sólo el ciervo de color rojo se encuentra perfilado por grabado en la región anterior del cuello (Beltrán, 1968: 148; 1986: 46) (Piñón, 1982: 151).

Coquinera de Obón (Obon, Teruel). Se hallaron dos bóvidos de tipo naturalista de coloración granate, uno de ellos de gran tamaño llegando a los $50 \mathrm{~cm}$. que se perfila su contorno con grabado, si bien no todos se han puesto de acuerdo en la existencia de este grabado.

Barranco de Calapatá (Cretas, Teruel). Se apreciaron por Cabré (1915: 137) silueteados y líneas grabadas para señalar ojos, nariz, boca, cuernos y parte de la musculatura del animal, pero los recientes estudios niegan su existencia.

Abrigo dels Gascons (Cretas, Teruel). Figuras arrancadas en paradero desconocido (Cabré, 1915) según este autor existían grabados sin pintura: cabezas de toro, cabras y un caballo. Almagro Basch (1945: 46) sin embargo no lo creyó y hoy sólo se admite la existencia de dos perfilados grabados sobre dos ciervos.

Roca dels Moros o dels Quartos (Cretas, Teruel). Después del descubrimiento fue publicado por Cabré junto a Vidiella en 1907, con este hallazgo se da a conocer por primera vez la existencia del arte levantino. Existieron duras diatribas por haber arrancado su descubridor este hermoso friso, del cual hoy tan solo se conservan tres fragmentos en el Museo Arqueológico de Barcelona. Como explica Beltrán (1968: 105) parece que esta brutal y drástica práctica ya la realizó Breuil, en Minateda, y Hernández Pacheco en Villar del Humo. Los animales más bellos representados pertenecían a tres ciervos de "arte naturalista minucioso" como dijo Beltrán. La técnica usada en este conjunto perfila las figuras previamente, mediante la técnica del grabado, el contorno de los animales que están rellenos de tinta plana con pigmento de color rojo-carmín oscuro. No existe ninguna representación humana.

Otros grabados fueron identificados por Cabré en unas rocas próximas al abrigo, pero según Beltrán estos grabados no existieron nunca.

Val del Charco del Aguamarga (Alcañiz, Teruel). De este abrigo ya destacó Beltrán en su día (Beltrán, 1968: 112) que estaba compuesto por 73 figuras. Una de estas figuras

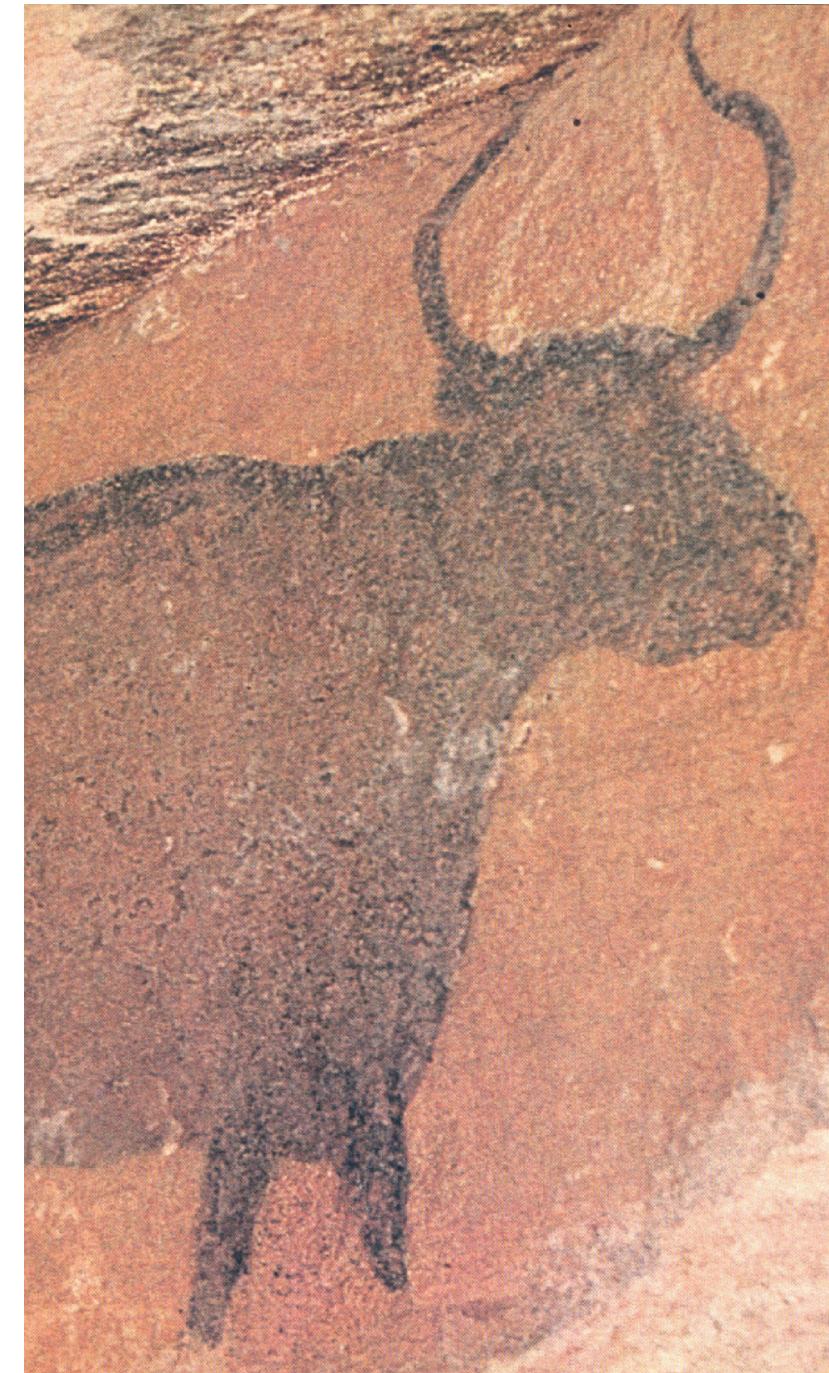

A Figura 6. Toro perfilado en grabado de Ceja de Piezarrodilla (Teruel).

presenta el perfil grabado parcialmente, no detallada que quizá pertenezca al gran ciervo de color rojo claro que se compara con los ciervos de Calapatá y Els Gascons.

Existen otros ejemplos en Teruel de la técnica del grabado como en el Mas del Abogat (Calaceite) o en Tajadas de Bezas (Albarracín) donde se localizó una cierva que presenta todo el contorno grabado (Beltrán, 1968: 145).

\section{LA CAUSA DE LOS CAMBIOS EN LA GRAFÍA POSTPALEOLÍTICA}

¿Por qué existieron cambios en las grafías postpaleolíticas? ¿Se deben a cambios de ideologías producidas por modificaciones socio-económicas? Nuestra respuesta es afirmativa ¿Son los estilos herramientas cronológicas? Creemos que no, puesto que a menudo éstos se combinan entre sí, especialmente en periodos de transición económica. 
Estas cuestiones, entre otras, nos podemos plantear cuando intentamos averiguar cual fue la causa de los cambios de ejecuciones estilisticas y temáticas en la grafía pospaleolítica.

Nuestra propuesta es la siguiente: el paradigma cronoestilístico a nuestro juicio no es válido como horizonte delimitador de etapas diferenciadas en el arte postpaleolítico. Sí, por el contrario, nos parece mucho más útil el análisis técnico y cronotemático para identificar cambios socioeconómicos y diferencias en las grafías de dichas expresiones.

Dicha propuesta necesita de una explicación para conocer sus causas, que en el fondo es muy simple. Creemos que nunca hemos valorado lo suficiente a los grupos humanos que efectuaron estas pinturas y/o grabados, creyendo erróneamente que el conjunto se debe a una sola etapa cultural.

En este sentido nosotros defendemos que su ejecución abarcó una serie de periodos culturales que no tuvieron ni la misma economía, ni la misma sociedad y por tanto no contuvieron la misma temática. En efecto, si analizamos los territorios en que se extienden estas expresiones pictóricas 0 grabadas en general se adaptan a los ámbitos en que apenas se encuentran trazas del llamado "arte paleolítico" y su sustitución viene dada por la presencia más genérica de el llamado "arte mobiliar" ya sea sobre plaquetas o cantos.

La masiva presencia de arte mobiliar grabado de raíz paleolítica se hereda en el Epipaleolítico a partir del 12.000 BP., la variación del eje terrestre, los cambios climáticos, la modificación de las delineaciones de costas, y la nueva adaptación de especies a este nuevo fenómeno climático, de comienzos del Holoceno, significó no sólo un cambio importante en los ecosistemas sino también un cambio socioeconómico de los grupos humanos que sin duda se tradujo en un cambio ideológico o de mentalidades.

Teniendo en cuenta esta realidad, no se puede obviar que sobre los mismos lugares o cercanos a ellos donde se realizaron en el Paleolítico superior estas representaciones grabadas y en casos pintadas, más tarde nos encontraremos con los testimonios de los grafismos al aire libre grabados 0 pintados de lo que se ha llamado "arte levantino". Nos parece muy importante esta proximidad territorial. Temática que ya hemos indicado en otras publicaciones (Olaria, 1999), y nos hace pensar en una clara influencia espacial que producirá como ya hemos dicho la aparición definitiva de las representaciones levantinas. Otro factor que muestra interés es que el territorio levantino más importante en número de abrigos y grafías más arcaizantes se sitúa entre Huesca, Lérida, Tarragona, Teruel y Castellón. Pero a medida que se extiende hacia el sur se hace más escaso y derivará hacia formas y contenidos más avanzados, enlazando finalmente con las grafías esquemáticas.

Por otra parte si analizamos los contenidos o temáticas de las expresiones más arcaicas, a nuestro juicio, nos expresan un mundo incontestable de cazadores de caza mayor (bóvidos, cérvidos y cápridos salvajes especialmente) $\rightarrow$ Epipaleolítico.

Este contenido cinegético fundamentalmente se modifica paulatinamente con la incorporación de escenas de recolección. $\rightarrow$ Mesolítico.

Para más tarde introducir escenas domésticas vinculadas a mundo agrícola, pastoril $\rightarrow$ Neolitización.

Finalizando con escenificaciones de orden puramente doméstico y con cambios de técnicas en la plasmación de las figuras y signos $\rightarrow$ Neolítico.

Citaremos algunos ejemplos de yacimientos conteniendo restos de grafismos que a nuestro juicio podrían pertenecer a distintas etapas culturales, como serian los siguientes:

- Epipaleolítico: Ave grabada de Cueva de Nerja (Málaga); Cueva de la Victoria (Málaga), Salón del Lago de la Cueva de la Pileta (Benaoján, Málaga) dos cabezas de animales estados se dataron estas figuras en 9.940 a. n. E; Tajo de las Figuras (Cádiz); arquero de la Cueva de Ardales (Málaga) donde debemos recordar se encontró una mandibula femenina de época epipaleolítica. Plaqueta grabada de Cova Fosca datada en 12.130 BP (10.180 BC); grabados de Tossal de la Roca (Alicante); grabados naturalistas de Abric d'en Melià (Serra d'en Galcerán, Castellón); escena levantina con arqueros de Abrigo del Barranco (Castellote, Teruel) es posible que marque el momento final de este periodo; y plaquetas de St. Gregori (Falset, Tarragona).

- Mesolítico: haces grabados de Cueva de las Vacas o del Tajo de Jorox ( Alozaina, Málaga); plaquetas grabadas de Cueva de la Cocina (Dos Aguas, Valencia).

- Neolitización: pinturas y perfilados en grabado como en Abrigo de la Cocinilla del Obispo en otros que ya hemos comentado.

- Neolítico: pinturas de temática doméstica como Abrigo del Pajarejo (Albarracín, Teruel) con una escena de tipo agrícola pintada en rojo; Abrigo del Tio Campano (Albarracin, Teruel) con una figura humana que lleva del ronzal un animal.

\section{LA CRONOLOGÍA}

Ante todo deberemos revisar las cronologías que se han obtenido para los yacimientos inmersos en territorios "levantinos":

- Por una parte no podemos obviar las cronologías obtenidas en los niveles en los cuales se han hallado plaquetas grabadas y cuyos yacimientos se encuentran en el interior del citado territorio:

1. Cova Fosca que nos ha dado una plaqueta grabada con dos cabezas de ciervas, fechadas en el laboratorio Beta Analytic de una muestra de carbón 12.130 
BP (10.180 BC) 15.310-14.650 cal. BP (13.36012.700) cal. $B C$ con industrias de tipo microlaminar y que situamos en el momento inicial del epipaleolítico microlaminar.

2. Cueva del Tio Modesto se realizaron tres muestras, aún inéditas sobre oxalato cálcico alrededor de las pinturas: $6.180 \pm 35 \mathrm{BP}(5.230-5010 \mathrm{cal} \mathrm{BC}) ; 5.855 \pm$ 35 BP (4.800- 4.610 cal BC); y $2.800 \pm 35$ BP (1.050840 cal BC).
Ambas dataciones nos presentan una horquilla cronológica de unos cinco milenios de duración total, lo cual expresa la larga tradición de grabado somero, por una parte, pero también a la vez la introducción de la aplicación de pigmentos, primeramente rojos, posteriormente blancos o negros y más tarde generalizándose los pigmentos rojos en todas sus gamas. Los 5.000 años de perduración gráfica con diferentes técnicas ilustrarían los cambios producidos desde el Epipaleolítico, Mesolítico al Neolítico antiguo.

\section{BIBLIOGRAFIA}

Almagro BasCH, M. (1952): El covacho con pinturas rupestres de Cogul (Lérida), Instituto de Estudios llerdenses, Lérida.

Almagro BASCH, M. (1956): Las pinturas rupestres del bajo Aragón. En M. Almagro, A. Beltrán y E. Ripoll. Prehistoria del Bajo Aragón, pp. 4195, Zaragoza.

ALonso, A. (2003): Los grabados parietales postpaleolíticos del sector mediterráneo peninsular, en I Congrés Internacional de Gravats Rupestres i Murals. Homenatge a Lluís Díez Coronel, pp. 273-305, Lérida.

Aparicio, J. (2006): Cueva de la Cocina (Dos Aguas, Valencia), en La Labor del SEAV de la Diputación Provincial de Valencia hasta 2005, Sección de Estudios Arqueológicos Valencianos (SEAV), Valencia.

ATRIAN, J. (1985): Avance al estudio de nuevos grupos con grabados rupestres en la provincia de Teruel. Museo de Zaragoza. Boletín n. 4, pp. $37-45$

Beltrán Martinez, A. (1968): Arte rupestre levantino, Monografias arqueológicas IV, Seminario de Prehistoria y Protohistoria, Zaragoza.

Beltrán Martínez, A. (1986): El arte rupestre en la provincia de Teruel. Teruel. Instituto de Estudios Turolenses. Cartillas Turolenses, n 5, Teruel.

Beltrán Martínez, A. (1998): Sacralización de lugares y figuras en el arte rupestre levantino del río Martín., BARA. Boletin de Arte Rupestre de Aragón. 1. pp. 93-116. Diputación General de Aragón Zaragoza.

BosCH GIMPERA, P. (1968): La chronologie de l'árt rupestre seminaturaliste et schematique, en "Préhistoire. Problèmes, Tendances», pp. 71-75 Burdeos.

CABRÉ, J. (1915): El arte rupestre en España (regiones septentrional y oriental). Museo Nacional de Ciencias Naturales. Madrid.

CABRÉ, J. (1915): La Val del Charco de Agua Amarga y sus estaciones de arte prehistórico. Comisión de Investigaciones Paleontológicas y Prehistóricas, 1. Madrid.

Cacho Quesada, C.; Jordá Pardo, J.; De la Torre SÁInz, I. y Yravedra SáinzDe los TerReros, J. (2001): El Tossal de la roca (Alicante). Nuevos datos sobre el magdaleniense mediterráneo de la Península Ibérica, Trabajos de Prehistoria, 58, $1^{\circ}$, pp. 71-93, CSIC, Departamento de Prehistoria. Instituto de Historia. Madrid.

CACHo, C.; Fumanal, M. P.; LóPez, P., et al. (1995) El Tossal de la Roca (Vall d'Alcalà, Alicante). Reconstrucción paleoambiental y cultural de la transición del tardiglaciar al holoceno inicial. Recerques del Museu d'Alcoi, IV,pp. 11-101. Ajuntament Alcoi. Alcoi.

ForTEA, J. (1975): En torno a la cronología del inicio del "arte levantino"(Avance sobre las pinturas rupestres de La Cocina), Saguntum. Papeles del Laboratorio de Arqueología Levantina, 11, pp. 185-197, Valencia.

ForTEA, J. (1976): El arte parietal epipaleolítico del VI al V milenio y su sustitución por el arte levantino, IX Congreso de la UISPP, Colloque XIX: Les Civilisations du 8é au 5é millénaire avant notre ère en Europe, UISPP, pp. 121-133, Nice.

GRIMAL, A. (1995): Avance al estudio de las pinturas rupestres de la Cueva de Cocina y su relación técnica con el arte levantino", Actas XXI del CNA, vol. Il (Teruel, 1991) pp. 317-325, Zaragoza.

Guillem, P.; Martínez-Valle, R. y Melí, F. (2001): Hallazgo de los grabados rupestres de estilo paleolítico en el norte de la provincia de Castellón: el Abric d'en Meliá (Serra d'en Galcerán), SaguntumPLAV, 33, pp.133-139.
LAPLACE-JAURETCHE, G. (1966): Recherches sur l'origine et évolution des complexes leptolithiques, "Ecole français de Rome", Paris.

Martinez-Valle, R.; Guillem, P. y Villaverde, V. (2003): El Abric d'en Melià. Grabados rupestres de estilo paleolítico en el norte de CasteIlón, Actas del Symposium de Ribadesella, pp. 279-290.

OLARIA, C. (1999): Arte, Hábitat y Territorio en el Mediterráneo peninsular durante el postglaciar. Un modelo de interpretación en el Norte del País Valenciano. Bolskan, 16, pp109-149, Instituto de Estudios Altoaragoneses. Diputación de Huseca.Huesca.

OLARIA, C. (2001): Pensamiento mágico y expresiones simbólicas entre las sociedades tribales del litoral mediterráneo peninsular 10000 7000 BP. Quaderns de Prehistòria i Arqueologia de Castelló, 22. pp. Diputación de Castellón. Server d'Investigacions Arqueològiques i Prehistòriques. Castelló.

Olaria, C.; Aguilella, G.; GómeZ, J. L. y Gusı, F. (2005): Población y territorio artístico levantino. Acerca del origen y evolución del arte postpaleolítico en "Arte rupestre en la España mediterránea», Alicante, 25-28 de octubre de 2004.pp.149-160 Caja de Ahorros del Mediterráneo; Instituto de Cultura Juan Gil-Albert, Alicante.

Pericot (1945): La cueva de la Cocina (Dos Aguas, Valencia). Nota preliminar, APL, II pp.39-75, Valencia.

Ripoll Pereló, E (1961): Los abrigos pintados de los alrededores de Santaolea (Teruel). Prólogo de Luís Pericot García. Monografía de Arte Rupestre. Arte Levantino, vol. 1, pp 35, Inst. Arqueología y Prehistoria, Barcelona.

Ripoll Perelló, E. (1968): Cuestiones en torno a la cronología del Arte Rupestre Postpaleolítico en la Península Ibérica, Actas del Simposio de Arte Rupestre. pp.165-194, Inst. Arqueología y Prehistoria. Barcelona.

Ripoll Perelló, E. (1981): Los grabados rupestres del Puntal del Tío Garrillas (término de Pozondón, Teruel), TERUEL,66, Instituto de Estudios Turolenses, pp. 147-155, Teruel.

Ripoll Perelló, E. (1990): Acerca de algunos problemas del Arte Rupestre postpaleolítico de la Península Ibérica, Espacio, Tiempo y Forma, serie I. vol. 3. pp. 71-104, Madrid.

Ripoll Perelló, E. (1990-1991): En los orígenes de la controversia sobre la cronología del arte rupestre levantino. Anales de prehistoria y arqueología. vol. 7-8 pp. 65-68 Universidad de Murcia, Murcia.

SEBASTIÁN, A. (1986-1987): Escenas acumulativas en el arte levantino. I Congreso Internacional de Arte Rupestre (Caspe, Zaragoza). Bajo Aragón. Prehistoria. VII-VIII, pp. 377-397.

SEBASTIÁN, A. (1992): Nuevos datos sobre la cuenca media del río Guadalupe: el abrigo de Barranco Hondo y el abrigo del Ángel. Revista Teruel, $n^{\circ} 79$, vol.II (1988) pp.77-92

UtRILLA, P. (2000): El arte rupestre en Aragón. Colección CAl, 100. Zaragoza.

UtRILLA, P. y VILLAVERDE, V. (eds.) (2007): Los grabados levantinos del Barranco Hondo, Castellote (Teruel), en Monografias del Patrimonio Aragonés, 1, Zaragoza.

VILASECA Anguera, S. (1973): Reus y su entorno en la Prehistoria, tomo I, Asociación de estudios reusenses, Reus

VILASECA, S. y CANTARELL, I. (1955-56): La Cova de la Mallada, de Cabra Feixet, Ampurias, XVII-XVIII, Barcelona.

WAA (2006): Arqueologia en blanc i negre. La labor del SIP 1927-1950, pp. 183-188, Valencia. 